\title{
How to Increase the Value of Digital Badges for Assessment and Recognition in Higher Education. A University Case
}

\author{
Elena TREPULE $\dot{E}^{1 *}$, Airina VOLUNGEVIČIENË ${ }^{1}$, \\ Margarita TERESEVIČIENE ${ }^{1}$, Rasa GREENSPON ${ }^{1}$, Nilza COSTA ${ }^{2}$ \\ ${ }^{1}$ Education Academy, Vytautas Magnus University, Kaunas, Lithuania \\ ${ }^{2}$ Research Centre for Didactics and Technology in Teacher Education, University of Aveiro \\ Aveiro, Portugal \\ e-mail: \{elena.trepule; airina.volungeviciene; margarita.tereseviciene; rasa.greenspon\}@vdu.lt, \\ nilzacosta@ua.pt
}

Received: June 2020

\begin{abstract}
The main goal of this research is to enhance the understanding of quality criteria for DB metadata for assessment and recognition as factors increasing their value in higher education (HE). To attain this goal, a case study approach centered in one HE institution was used, aiming (a) at an analysis of the status quo description of metadata of DBs issued by the HE institution to identify the value of DBs in terms of assessment and recognition procedures, and (b) a list of quality criteria for DB description metadata was proposed on the basis of academic research and on expert interview results. The results of the research demonstrate that in the institution under research, these criteria are not present in most cases of DB descriptions as teachers do not provide them. Distinct assessment and recognition criteria make an important quality factor for the DBs to become valid and valued digital credentials in HE.
\end{abstract}

Keywords: digital badges, metadata, criteria, assessment, recognition, higher education.

\section{Introduction}

The origin of digital badges can be traced back to their historical cloth predecessors: Scout organizations used to indicate the skills that girl and boy scouts had gained and could wear them attached on their scout uniforms. Initially DBs were mere graphic image representations, so they could be easily copied and used without sufficient proof of their authentic achievement. The new DBs (Catalano and Doucet, 2013) offer solutions to the initial learning problems by embedding metadata inside the image that provide

\footnotetext{
* Corresponding author
} 
information as to how it was earned by the learner and who the issuer was, while the technical standards allow sharing DBs with others.

Numerous studies on DBs in HE demonstrate different scenarios of their use (Rimland and Raish, 2019; Roy and Clark, 2019) and new developments, as this technology gains more adaptability. Also, the application of DBs is diversified (Zucker and Hicks, 2019; Carey and Stefaniak 2018; Parker, 2015) and ever-changing. Meanwhile, teachers at universities lack knowledge, procedures, or trust in DB development and face challenges (Kehoe and Goudzwaard, 2015; Waters, 2013), especially in the assessment strategy and recognition of the knowledge or skills that their students achieve. Contemporary DB are no longer single visual picture badges but contain metadata within that provides exhaustive information about the tasks performed, criteria of their assessment, the time needed to perform and the volume of the task, etc., that serves in increasing transparency of assessment by communicating much more information than a single grade or certificate could have.

To attain this goal, a case study approach, centered in one HE institution, was used aiming (a) at an analysis of the description of metadata of digital badges issued by the HE institution to identify the value of DBs in terms of assessment and recognition procedures, and (b) a list of quality criteria for DB description metadata was proposed on the basis of academic research and on expert interview results.

Thus, the qualitative inquiry is supposed to provide answers to the following research question: which quality criteria of assessment and recognition need to be included and described in DB metadata to add the value of the digital credential for assessment and recognition in HE?

This article is structured in six sections. Besides the Introduction, the main dimensions of the Theoretical Framework are presented. Further it includes a Methodology section, a section on Research Limitations, Findings, and Conclusions. At the end of the article References are listed.

\section{Theoretical Framework}

As the focus of this research is DBs in HE, the discussion should start by exploring recent literature to identify the concept of DBs, their potential, the variety of ways they have been used, as well as challenges they are still raising in the context of HE. It should be noted that there exists a considerable number of studies about the use of DBs in HE, yet recent literature still considers the need to develop this topic of research (see e.g., Stefaniak and Carey, 2019) further, to better understand and give credibility to DBs in HE.

\section{Multidimensional Concept of Digital Badges}

There are several ways in which researchers have been defining the concept of DBs, particularly in the context of HE. Drawing a summary of the main emerging dimensions of DBs, the following are to be taken into account: 
DBs are electronic symbols (Stefaniak and Carey, 2019) used for several purposes, e.g. for documenting performance and achievement; as micro-credentials (Carey and Stefaniak, 2018), which may link, in a meaningful way, the worlds of education, work and community (Muilenburg and Berge, 2016).

DBs could be a form of micro-credentialing, to recognize and evidence accomplishments acquired through non-formal learning experiences or tracking learning that might otherwise go unrecognized through academic processes (Dyjur and Lindstrom, 2017), or may be seen as a way of tracking learners' progress in formal studies. The potential of DBs is explored as having an effect on increasing students' achievements (Mah, 2016), students' motivation (Iwata et al., 2017), and opportunities to peer review and feedback (Stefaniak and Carey, 2019).

DBs can offer a transparent way of representing academic achievements through digital metadata. There are three main ways to apply DBs (Stefaniak and Carey, 2019), namely, at an individual course level (1), program level (2) and at university level (3). These may be implemented when a DB is introduced in a given course and any student may choose to earn a digital badge (1); when a given program adopts DBs, and teachers of different courses may choose to use them in their courses (2); and when DBs are adopted by the university (3) and they are incorporated in learning management systems or virtual learning environments. All these scenarios and the potential seem reassuring, but we need to further link the new trend of the digital credentials in the form of DBs with the classical processes of education, where they seem to have the potential to be embedded.

As a deviation from the list of the concept definitions, it should be mentioned that the traditional university setting trusts paradigms of academic credentialing and educational assessment more and is not particularly keen on including a new type of credentials in the form of DBs since they tend to transform education and learning (Casilli and Hickey, 2016). Nevertheless, the use of DBs in HE has been studied for different purposes (Abramovich, 2016), namely: (a) to influence students' engagement and learning (e.g., the earning of a DB may motivate a student to learn); (b) to assess learning (e.g., in classroom) in formal and less formal (e.g., in autonomous work) contexts (Abramovich et al., 2013); (c) to certify certain achievements by giving a micro-credential to a student; and (d) to add value to academic and professional development, in particular to enhance employability. The feature of DBs to provide evidence in the form of digital credentials could be attractive for HE students, who are willing to demonstrate specific skills to future employers that are not otherwise visible in the official university transcripts. Besides, the acquisition of digital credentials is important for students who are in the process of degree studies and need to supply documentation of their skills for employers, scholarship applications, internships or placements, and for those who have gained certain skills and completed some coursework but are not able to complete their full degree (Wu et al., 2015).

To continue with DB dimensions: DBs require clear internal institutional decisions on the ways the badges will be created, developed, and issued, and these preparations require significant time investments (Rimland and Raish, 2019). With respect to HE institutions, one highlights the recommendation of Ifenthaler, Bellin-Mularski and Mah 
(2016) that DBs are a relatively new technological solution and, therefore, their acceptance depends on the level of quality control, the actual design, and their development solutions in virtual learning environments.

From the dimensions above, one can see that DBs are a multidimensional concept and that two major arguments for the use of DBs in HE may be highlighted, namely, students' learning assessment and recognition of achievements, as these two are directly and unquestionably embedded in HE practices and policies. We will focus on these purposes next.

\section{Digital Badge as a Part of Assessment Strategy}

In 2016, The Bologna Open Recognition Declaration by the Open Recognition Alliance called for a universal open architecture for the recognition of lifelong learning achievements. One of the major potentials identified in education policy was the development of open recognition technologies and infrastructure. HE and stakeholders received an invitation to establish a trustworthy system of human and machine verifiable learning credentials and to adopt open standards facilitating the comparability and transferability of learning credentials. This entails that HE establishments are invited to review their assessment strategies possibly providing more metadata information in their assessment strategies.

The development of assessment strategy is an important part of any type of learning and teaching process, whether it happens face-to-face or online. However, online learning environment sometimes brings more challenges than the traditional one and requests new instruments to be used. Specifically, e-portfolios, learning journals, projects and group work are identified as tools that can be used to engage online learners and can offer effective means for authentic assessment (Fanfarelli and McDaniel, 2017). The transparency of assessment strategies, e.g., the criteria to be used, and involvement of learners in discussing and negotiating with them the ways their learning results will be assessed are crucial for assessment practices. Technologies can help bring this process to better transparency, to involve learners into assessment strategy development, and to structure the assessment and recognition process (Haldane and Wallace, 2009).

DBs with the metadata information that they entail, as well as other digital tools, may enhance assessment practices and enrich them with a variety of forms and techniques. Tests, quizzes, and written papers are often used to demonstrate learning outcomes, however more complex evidence may challenge assessment strategies when workshops, projects or other course activities are organized. DBs have been successfully tested in university graduate research programs to assess acquisition of necessary research skills and serve as a certain roadmap to skills necessary to attain during research studies that are not too structured in terms of constant course work (Mewburn et al., 2014).

Soft skills can also be assessed and graded by awarding DBs in order to disclose the learner's personal development (e.g., persistence, self-regulation, problem solving, divergent and lateral thinking, creativity), as well as her/his social participation (e.g., collaboration, communication, negotiation, teamwork, networking, leadership, 
emotional awareness, differentiation of contributions) (Law, 2015; Zucker and Hicks, 2019). Besides, introduction of DBs in higher education brings transparency to teaching, learning and assessment, as they could reveal identifiable and detailed learning aspects for all stakeholders and provide a new mechanism to recognize skills, experience and knowledge through open, transferable and stackable technology framework (Gibson et al., 2016).

The arguments above do not leave doubt that DBs are proved to be suitable assessment strategy elements, albeit it is not clear under which conditions and requirements they fulfill their mission correctly. We predict that in all cases the quality of the DBs as an assessment strategy element is imbedded in its criteria and in the description of metadata template of the credential, which may be of greatest importance.

\section{Digital Badges for Recognition of Competences}

As argued above, multidimentional use of DBs serves different purposes. One of the potential and popular uses of the DB credential is associated with the recognition process of skills and competences which are not always described in curricula or which are additional skills and competences achieved during the learning process.

The research describes how DBs can serve as a tool to recognize accomplishments acquired outside the university during non-formal learning, professional development (Dyjur and Lindstrom, 2017), or outside the immediate community, as part of volunteering activities in one's own university. The issue how to recognize non-formal learning in a formal learning curriculum remains a great challenge, despite the growing need for such recognition and the prospects that digitalisation of universities create.

Many researchers and recognized international organizations (e.g. Bjornavold, and Le Mouillour, 2009; Singh, Duvekot, and UNESCO UIL, 2013) discuss the potential of the digital era in turning recognition of learning outcomes into a trusted and accepted way of acquiring qualifications and opening up a wider range of potential pathways to certification and recognition practices.

We argue that DBs if supported with sufficient metadata can be data rich recognition instruments that can support learners in their individual learning path. Badges have a potential to catalyse the shift from traditional credentials to the ones that measure competence achievement through scalable descriptions, which carry important quality criteria in line with assessment and recognition processes. All learning experiences and learning achievements need to be recognized, and DBs allow learners to require micro-credentialisation of learning and to achieve visible proof in digital spaces of their learning assessment results and their recognition (Duncan, 2011). Degrees or credentials supported by a transcript of grades still comprise the main credentials in the traditional $\mathrm{HE}$, yet, recently, micro-credentials have begun to increasingly appear due to evolving practices involving DBs (Gibson et al., 2013).

We strongly believe, just as other researchers do, that DBs may serve as a first step in transparent assessment and recognition processes, which may be further developed to external and complete recognition of learning results through open DBs in the future, 
recognizing skills that learners could transport and display via their social network accounts (Devedžić and Jovanović, 2015). Therefore Cheng, Watson and Newby (2018) propose to agree among all stakeholders on the categories of knowledge, goals, and competencies of each badge layer; and on the label of badges and the amount of information in a single badge.

Digital badges as a contemporary form of digital assessment in non-formal as well as professional development environments may find their way in the formal assessment and recognition in higher education as well. DB allow connecting academic courses to most recent knowledge and data that are found in the practical world of work and industry. When providing sufficient metadata that is adequate to the information needed for academic recognition, DB gained outside academia could be recognized as part of degree program and vice versa - the DB issued by the university could complement the portfolio of competencies needed for employers that are otherwise not chartered in the academic transcript. Thus encouraged by the research literature we continue with a discussion on what kind of criteria should be defined for the description of DB metadata in their technical templates and what added value these may have for DB in assessment and recognition processes.

\section{Role of Digital Badges Metadata}

DBs inform students how they progress, which skills and competences they have demonstrated (Boyer, 2018), they symbolize achievement, learning and growth, but this happens only if they contain verifiable metadata, revealing the criteria met, evidence (e.g. project, creation) provided, and credify these achievements by confirmation or testimony of the issuer of the credential. All said, there still are miscommunications and disagreements among stakeholders who produce and recognise DBs (Cheng et al., 2018; Waters, 2013), namely, on which information should be included in the description metadata of a DB. Most often the name of the issuing organization, the date issued, and the requirements in the form of an activity are indicated in the description of the DB (Dyjur and Lindstrom, 2017). However, "digital badges offer the additional affordance of embedded metadata that can link to the criteria for earning the badge, evidence of the skill, and other information including issuer details" (Carey, 2017, 3).

Researchers agree on the need of setting criteria for DBs and on the importance that they should reflect students' achievements/learning outcomes that DBs are going to represent (Kehoe and Goudzwaard, 2015; Parker, 2015). Moreover, questions have been raised on the use of data from learning analytics about learning traces, as together with the criteria they could give valuable input to the badge development (Devedžić and Jovanović, 2015). Metadata descriptions provide guidance for educators in and out of traditional learning contexts (O'Byrne et al., 2015) as they may contain specific criteria and evidence about learning and achievement along with detailed evidence supporting those criteria.

Ideally, badge designers use reliable and valid assessment and recognition criteria built into the badge system, however, as practice often shows, in many cases the criteria 
for the description of DB metadata are still underexplored. Often, designers of DBs in virtual learning environments have little pedagogical guidance on how much and what kind of information should be inserted in DB description metadata (Cheng et al., 2018). Even if teachers might add important assessment and recognition criteria in DB description templates, technological support (Jones et al., 2018) is important: academic staff must understand how DBs are issued, which metadata are visible for students, and when, as not every HE teacher is aware on how to ensure that the evidence of learning results is compatible with the DB description. These challenges may lead to increased faculty workload and usability issues, such as misunderstanding of the purpose and value of the badges.

\section{Methodology}

The backdrop of this study is the university where most of the authors of this paper are employed. It is a modern university in Lithuania which promotes technology enhanced learning, is constantly upgrading software tools to enrich learning experience. It offers studies in three different learning settings, including face-to-face classrooms, blended, and online learning mode. A case study approach was used in the empirical research component, based on a content analysis of the metadata. The analysis included two stages.

The first stage research results allowed identifying the main reasons why DBs are issued to students and what information is available in the metadata descriptions, including the types of DBs. Further, descriptive statistical analysis has been applied to observe the frequencies of how often and with what type of DBs students are awarded.

13 different study courses were selected from virtual learning environment where DBs have been created, activated, and issued to students. The courses for content analysis have been selected with the assistance of a Moodle administrator. All of the analyzed study courses belong to either humanities or social sciences. Besides, the analyzed courses are designed for blended or fully online learning modes. Digital badges are created and used in virtual learning, i.e. in Moodle environment. In order to create and activate a DB, the teacher has to fill in a DB description template that is provided within the virtual learning environment: they have to name the DB, to add its purpose and description elements, an image, and, finally, select its expiry date. The results of the first stage have helped to discover how DBs have been developed and used in the given HE institution, particularly in terms of students' assessment and recognition.

In the first stage (1), data has been collected using virtual learning environment (i.e. Moodle) as a chain of evidence for exploring the main reasons why DBs are awarded to students; also for finding out categories for assessment and recognition in metadata of DB descriptions developed by teachers. A content analysis of the metadata of DBs has been performed to find out information on their type and purpose, while descriptive statistical analysis has been applied to observe the frequencies of how often and with what type of DBs students are awarded. Considering the fact that the vast majority of digital badges has been created and issued in social sciences and humanities, the research fo- 
cuses on these two study fields. The sample for the content analysis is 13 different study courses, taught starting fall semester of 2015 up to fall semester of 2019, in two different study fields namely Humanities and Social sciences with 320 digital badges in total.

DB are created and used in the virtual learning platform, i.e. Moodle, and, once they are issued, they can be seen by all Moodle users. Teachers are responsible for creating badges that are awarded to students. In order to create and activate a DB, a teacher has to fill out a template, which is provided by the university within the virtual learning environment: they have to name the digital badge, add its description, image, and, finally, select its expiration date (Table 1). This description later serves as the metadata for the DB. Any further users with a link to the DB (e.g., in a CV) may receive exhaustive information about the details of assessment of gained skills or competencies as well as other information about the issuer of the badge, date of issue and expiry date if applicable. This metadata information provides more value to the holder of a DB as well to those who are concerned.

Once the criteria are set and the DB is created and activated, it can be categorized in terms of its purpose. This, as it will be seen below, is to motivate, to assess, or to

Table 1

Existing Development of a Digital Badge at University

\begin{abstract}
Badge Details
Name Badge name should be short and the content of the achievement should be easily understandable.

Description Description should provide the details of achievement: describe the context, specify the achievement, refer to completed tasks, and explain the assessment procedures. Useful tips on how to write a good badge description are available here[1].

Image In a process of preparing the image, one should bear in mind that image will be the main representation of the badge. It should be simple, without too many details but still interesting enough for someone to want to see the rest of the information.
\end{abstract}

\title{
Issuer Details
}

Name Name of the issuer is a name of the individual, entity, or organization that issued the badge.

Contact Issuer's contact information.

\section{Badge Expiry}

Expiry Date This is the information about the expiry date of the badge, if there is one. Options are: never, fixed date, or relative date. This date is usually set for certificates that need to be re-accredited after a period of time.

\section{Criteria}

Criteria Criteria provides information about the task needed to be completed by badge earner to receive a badge. There are several options, among others:

- Manual completion by role: if using this option, we have to choose the role we want to be able to award the badge

- Course completion: for using this option, tracking must be enabled for the course

- Activity completion: like for the previous option, the course tracking must be enabled

The selected criteria will be displayed among all the other digital badge data. In Moodle, for instance it means that all activities connected to the badge will be displayed. If you want to control what is displayed, use Access restrictions and Activity completion so that all other activities will lead to the one that the badge will depend on. 
recognize certain features such as punctuality, creativity, thoroughness, activeness, and skills or competencies. A note should be made that university is offering is a training course for teachers who are willing to create digital badges in their study courses. DBs and their metadata descriptions, that were used for the analysis, may be retrieved in the Moodle VLE.

During the first stage (1), content analysis was performed for analyzing DBs in Moodle platform and their metadata as examplified in Table 1 in terms of their design and application for students. A note should be made that teachers not only create DBs by composing the description, choosing image, setting the criteria that have to be met in order to receive a $\mathrm{DB}$, but also they are the ones who decide who is going to be awarded a DB. Naturally, it tends to be rather subjective if compared to the procedure when the system itself awards DBs to students when they meet predefined criteria - then the assessment process becomes impartial.

The second stage of the research is focused on the development of quality criteria for DB description metadata. The aim of the stage is to build a value proposition for assessment and recognition in $\mathrm{HE}$.

In the empirical study, the semi-structured interview method has been chosen. The purpose of the interview is to disclose the quality criteria for DB description metadata and obtain more targeted and detailed answers: if the informant would not answer a question for a reason, it could be supplemented or asked differently. The interview was performed with experts who have experience in open learning assessment and recognition.

In stage two, to identify and select interviewees who are most knowledgeable in the research area, share similar characteristics, and are able to provide data related to the research question (Creswell, 2013), the study participants were selected according to the established criteria: 1) interviewees had to be experts in recognition of open learning in $\mathrm{HE}$ or to be HE policy advisers; 2) represent HE institutions that have experience in using and issuing DBs.

Twelve international experts from European HE institutions having knowledge and experience of the recognition of online learning, DBs included, agreed to share their experiences and insights on the research topic. There were six men and six women from eight countries. The international group of research participants dealt with the following aspect of the research question: which quality criteria of assessment and recognition need to be described in DB metadata to add value to the digital credential for its broader application in assessment and recognition in institutions of HE?

During the second stage (2), interviews were performed for data analysis in spring 2019. There were five guiding interview questions formulated on the basis of theoretical analysis: questions on existing practices, challenges, requirements, criteria and evidence of assessment and recognition using DBs for online learning in higher education institutions. The interviewees were contacted personally by the researchers, introduced to the research aim and interview guidelines, and asked for their consent to participate in the research. Each research participant agreed to share his or her expertise via face-to-face or synchronous online meetings, using digital tools what allow researchers to follow the set of questions prepared in advance and rearrange the sequence of questions when needed. 
All the data was collected in English, audiotaped and transcribed. Research participants were given codes (I.1, I.2, I.3 ...I.12) to ensure confidentiality of research results.

During the second stage (2), inductive qualitative content analysis was used to analyze research data following the steps indicated by Creswell (2013), Bernard, Wutich and Ryan (2016). Following the procedure of content analysis allowed the authors of this paper to review categories and subcategories, and discuss the compliance among them by identifying the quality criteria for DB description metadata.

The combination of the two stages allowed the object of the research - the quality criteria of DB description metadata - to be studied in a wider context.

\section{Research Limitations}

In the first stage, this research was limited by the following factors: the analysis of the metadata was performed in only one university; the number of DBs that were available for the analysis was small; the number of study fields where DBs had been used was limited; certain study courses lacked access; DBs had a short expiry period.

In the second stage, only 12 international experts participated in the qualitative study as interviewees, thus the results of the study cannot be absolute, however, the criteria identified for digital badge description metadata show a reasonable direction and can be further expanded in the future to increase the quality and value of the use of DB for assessment and recognition in $\mathrm{HE}$.

\section{Findings}

\section{Results from the Content Analysis of Existing Metadata Descriptions of DBs}

As the content analysis has indicated, DBs are primarily issued for university students for the purposes of assessment. However, it should be stated that all DBs (320 in total) are used for the assessment of soft skills. The vast majority of DBs $(280$, i.e. $87.5 \%)$ has been used to assist in assessment procedures when grades are dealt with, while only 40 DBs (12.5\%) have been used to acknowledge students' soft skills. All the badges have been issued by the university teachers. The university uses the Moodle learning environment, where only registered users can see information about other users within the mentioned learning environment. The analysis has revealed the fact that to make them visible and open outside the internal learning environment of the university, a recipient of a digital badge has to export the badge to another, unrelated platform, and then create portfolios of badges that can be seen on various external social network platforms. Finally, the analysis of the metadata descriptions suggests that the vast majority of badges have been issued in courses taught in a blended mode.

Another important thing to be mentioned is that the descriptions of DBs do not provide any information on the type of learning. Based on the context, it can be stated that 
badges have been issued in ECTS accredited formal learning settings where the main goal is to provide certifications and degrees. As the analysis has shown, none of the DBs has been used in an informal learning setting. Finally, it should be mentioned that the metadata descriptions do not provide any information on the volume of learning. To be more precise, there is no information on the number of ECTS credits indicated in the metadata descriptions. Such information can only be received by looking up the course information, using external sources, or having access to the particular courses on Moodle. Due to limitations of the ethics of the research, access has not been granted to examine these courses.

The analysis of the metadata descriptions has suggested that DBs are related to several types of learning outcomes, including responsibility and autonomous learning and acquisition of knowledge. The vast majority of DBs (308 of320 DBs, 96.3\%) has been used as indicators of students' development as responsible learners and promotion of autonomous learning. In the meantime, only $12 \mathrm{DBs}(3.7 \%)$ have been given to students to indicate the fact that they have completed a course and have acquired new knowledge. Besides, badges are also used as indicators that students have fulfilled the requirements for the acquisition of a badge. In the meantime, badges that are used to indicate certain personal qualities, e.g., punctuality, can also be related to learning outcomes such as developing capacity for being an autonomous and/or responsible learner. In addition, the analysis has shown that there is neither evidence of learning outcomes nor any information on the EQF (European Qualifications Framework) level in the metadata descriptions of DBs.

Again, the vast majority of DBs has been used as a contribution to the assessment process. The analysis of metadata descriptions of DBs has shown the fact that teachers tend to award students with a badge which is used as an indicator that the student will receive a ten percent increase in the specified graded item, such as midterm or final. The analysis has demonstrated that teachers are the only assessors; no alternative assessment practices, such as self-assessment, peer assessment, or third party assessment, have been used. Additionally, the content analysis of metadata descriptions provided the information that in the vast majority of cases grading procedures are done manually. However, even though grading schemes are not explained in a detailed manner in the metadata descriptions, it can be assumed that assessment combines both formative and summative practices because in most cases students are asked to perform various tasks, which they receive feedback on, and then at the end of the course there is always a summative assessment procedure performed.

Moreover, the analysis of the metadata descriptions has suggested that students can expect such award if they perform the following tasks: actively engage in discussions in discussion forums, submit their homework on time, attend more than 95 percent of physical classroom meetings, and demonstrate a high level of skills and knowledge in their homework assignments.

However, the analysis has demonstrated that badges are not used as substitutes for any actual grading activity, i.e. midterm, homework, or exam. Thus, it can be stated that DBs are used as a supplementary element in the assessment process. 
In the meantime, the analysis of metadata descriptions has demonstrated that the application of badges, which are used to assess students' individual soft skills, features, and achievements, or to assist in assessment procedures, is directly connected to individual activities, such as participation in discussion forums, and writing of reports or essays. Unfortunately, due to poor metadata descriptions, it is impossible to provide examples of the individual activities. The analysis of the metadata descriptions of DBs does not provide any evidence on the procedural requirements for learner identification.

To sum it up, the analysis has shown that badges are used to prove assessment soft skills and to acknowledge certain features of students. At the university of this research, badges are not used for certifications, degrees, marking skills, and qualifications, nor recognition of prior knowledge, certifications, etc. The analysis has shown that badges are only issued within the learning environment, no evidence is provided of importing badges from external sources to the university's Moodle platform as evidence of certain skills or qualifications.

\section{Quality Criteria for DB Description Metadata for Assessment and Recognition in $H E$}

Recognition of skills and competences achieved during online learning process or participation in open online courses is not a generally accepted practice at HE institutions. Our respondents from European institutions of higher education have provided us with insights that significantly enriched our research. Content analysis of the qualitative interview allowed us to identify categories and subcategories for DB description metadata (Table 2). The compliance among the manifesting categories and subcategories allowed us to analyse assessment and recognition as two independent categories, but inseparable at the same time. Therefore, the results are presented in terms of the subcategories, no matter whether they refer to assessment or recognition.

Table 2

Categories and subcategories for DB description metadata

\begin{tabular}{ll}
\hline Categories & Sub-categories \\
\hline Assessment & Type of learning outcomes \\
& Type of assessment \\
& Procedural requirements for learner \\
& Type of learning outcomes \\
Type and scope of learning & Level of learning according to qualification framework \\
& Mode of learning \\
& Activity type \\
& Volume of learning \\
& Decision making \\
& Grading format of assessment \\
\hline
\end{tabular}




\section{Type of Learning Outcomes}

Types of learning outcomes have been highlighted by experts as important information for both recognition and assessment processes, as evaluators are "interested in knowledge, value, expertise, skills" (I.9). In case of assessment, this information would not only clarify the achievements (knowledge, skills, responsibility, or autonomy), but also would give more transparency to the process, as mentioned by the expert:

"So, they [universities] take one big course, let's say 4 ECTS, and divide the curriculum of this course into smaller parts which are described in terms of skills and competencies, and then digital badges or other types of credentials are issued to the learners, whenever this is completed". (I.1)

Indication of learning outcomes and competences allows evaluators and DB issuers to speak the same language, thus it is an important part of metadata in DB descriptions.

\section{Type of Assessment}

Experts think that both, formative and summative assessment strategies should use DBs. There could also be assessment methods that include some criteria of attendance, checking, lab work, assignments and papers that could support formative assessment strategy. The data from the interviews supports the opinion that DB data should reveal what kind of skills are assessed or whether the badge is issued for participation and student motivation:

"[Badges are] ... quite well designed, so normally one can see from a badge whether it was just a participation badge, or somebody had to make really hard essays or exams to get this badge". (I.3)

When assessment criteria in DB metadata are discussed, the type of assessment for learner authentication and identity (ID) verification are highlighted by experts.

\section{Procedural Requirements for Learner}

Experts emphasize that the most important point is the learner authentication in online enrolled assessment practices. How do you know that the person who is taking the exam, writing the report, or submitting the essay is the actual person who has been and studies the course? What procedural requirements for learner authentication and ID verification could be included in the metadata of the DB? According to the experts there are certain approaches and standards also for that. There are some good practices, for example virtual proctoring,

"biometrics (facial recognition, voice recognition, keystroke dynamics); security techniques (timestamp, digital signature)". (I.4), "So any recognition framework needs to take into account documenting how you have actually verified the identity and how you've done the assessment". (I.2) 


\section{Type and Scope of Learning}

When recognizing learning, experts indicated that DB description metadata should indicate also the type, scope of learning, e.g., for what kind of learning offering the credential is issued: for short learning programs, ECTS based non-formal courses, non-formal courses (not ECTS based), informal learning activity evidence, ECTS based informal learning activity evidence, competence-based non-formal learning course/ activity, competence-based informal learning activity, or other. Evidence would be helpful when used for recognition of the achievement for either the whole or a part of the study program, or perhaps for only a small part of one study subject or module:

"For example, support of a degree or part of some major or minor studies or some other programs or whether you are using some of them within a smaller module". (I.6)

\section{Level of Learning According to Qualification Framework}

The process of assessment and recognition when using DB should be aligned with the European Qualification Framework (EQF), which is an important translation tool for qualifications within the European Union, or national qualification frameworks of specific countries. For this reason, a level of learning based on European or National Qualification framework (NQF) should be indicated, as pointed out by experts:

"Obviously links to EQF are important, [...], I mean the reason these frameworks have been developed is that it made sense at a time we needed a standardized mechanism for talking about certain kinds of learning and teaching”. (I.10)

"I think for any kind of recognition of learning or how you store for example some educational data in any database or whatever, they need to be aligned with some hopefully international standards". (I.6)

“...for learning to be recognized and to be assessed, you need to relate it to qualification frameworks that exist, that ensure trust, ensure standardization". (I.11)

\section{Mode of Learning}

When discussing recognition issues, experts are concerned with the mode of learning. There are online, face to face, blended, placement, workplace, and even more modes when DBs are or can be applicable.

"..if the student is getting an online training via a private company from somewhere in Europe which is not known, he does not know, if this online course really adds value or not.... or from both sides, also from the company side, they need to see some kind of assessment, mode of learning, and quality criteria, and definitely it's a must for the institutions so they should have some requirements". (I.5) 
The mode of learning provides a wider context for recognition. The emphasis is not only on the mode of learning, but also on requirements, quality criteria for institutions both providing and recognizing learning. Providing as many details as it is reasonably possible could be important for recognition as it secures transparency of procedures.

\section{Activity Type}

Accordingly, information about activity type needs to be considered as evidence for the learning process, e.g. a workshop, a seminar or a conference, a discussion, a group work, a teamwork, an individual work, an internship /a placement, an apprenticeship/ shadowing or project work. One of the experts emphasizes the importance of all information on student experiences as it contributes to the recognition procedure:

“...some students are just good at writing exams, they might not have the skill, they might not have the competence, but they are very good at writing exams and others are not... ...So, we are trying to eliminate exams, and use more of, for example, group exercises, where you do life projects with companies, or maybe a hypothetical project, and you work on that, so team building skills are very important, you cannot work alone in these environments". (I.12)

\section{Volume of Learning}

The volume of learning is also indicated by the experts as important to be represented in DB description metadata, in a form of ECTS and contact learning hours:

“...how many hours are we claiming that this person has been doing this kind of learning so we can actually say that's equivalent to have done this sort of course". (I.10)

Experts suggest that the volume of learning may be reconsidered in the light of preparation to the learning process, so that the curriculum may be divided into smaller units. They think that DBs may serve as a good tool to approach more open and flexible ways of learning, integrating traditional principles of the process of recognition into assessment strategy:

"I think the first thing for universities is to introduce digital badges and digital credentials, and try to think how to divide curriculum on the basis of learning results to such small units that would be logical for teachers and study program committees, but at the same time that teachers would be able to describe in terms of skills and competencies, there're specific ones, so that they can be prepared to micro credentialization of curriculum of courses. So, they take one big course, let's say 4 ECTS and divide the curriculum of this course into smaller parts which are described in terms of skills and competencies, and 
then digital badges or other types of credentials are issued to the learners, whenever this is completed, and the next step for university I think is to prepare to demonstrate these digital badges in public spaces, so that they are openly visible for anyone who would be interested in employing or starting collaboration with people having such skills". (I.1)

\section{Decision Making}

Experts claim that there are more factors for DB description metadata quality, some related with the assessor. In cases when the assessor is not the teacher, but an independent assessor, or assessment is organized in peer-assessment or self-assessment practices, additional indication is needed in DB description as well:

“...very often, a person who is dealing with the recognition may not see the entire process of assessment and of awarding credentials, yet they know that they trust their end product"(I.7).

If information is a DB description metadata and evidence can be presented, it builds confidence in the assessment.

"You always have to be clear enough on the course itself, the issuer, the learner himself and the other theoretical considerations to be as transparent as possible to show what real examination was done behind the given badge”. (I.3)

\section{Grading Format}

Regarding the format, both automatic and manual grading and badge issuing can take place, but again, this information should be available in DB description metadata. Such information also contributes to transparency and quality of assessment process, as presented below:

"So it says for what learning activity it was given whether it was manually set or is automatically set. If it was automatic whether it was test based, what was the level of compliance - all those things have to be clearly stated. (I.3)

The results provided above demonstrate directions in answering the research question: which quality criteria of assessment and recognition need to be described in DB metadata to add the value of the digital credential to assessment and recognition. The analysis of experts' interview reveals the main quality criteria that should be defined in the description of DB metadata in their technical templates and what added value these may have for DBs in assessment and recognition processes. Clearly, more information is needed to recognize results than just information about the fact of their achievement. Besides, in both processes clarity regarding what is going to be assessed and recognized is crucial. When DBs are employed, there is a need for general data 
criteria, general information, e.g., learner's name, ID number. General data is important for an assessment and recognition procedure. This includes the type of badge (open DB or DB) and the data on the issuing institution - name and type. A variety of institutions can provide online courses including employer organizations, MOOC providers, professional organizations, and chambers. DBs may serve for recognition of learning outcomes achieved during the learning from the inside of the same university, as well as offered by the third party - for example, an education provider of continuing education, MOOC, an employer organization, a professional organization/ chamber, industry. Besides, the category of the badge demonstrating whether it is a recognition of formal qualification, or a non-formal certificate, or a record of experience must be indicated.

Table 3

Quality criteria for DB metadata description template (to establish the value of DBs for assessment and recognition in $\mathrm{HE}$ )

Quality criteria that need to be visible in DB description metadata template in virtual learning environment

Assess- Recogment nition

Information about the learner (name and ID number)

Type of badge (open digital badge; digital badge)

$\mathrm{X} \quad \mathrm{X}$

Name and type of the issuing institution (HE institution; continuing education institution; online/MOOC provider together with a HE institution; online/MOOC provider; employer organization; professional organisation / chamber, etc.)

Type of learning (short learning program (qualification, modular, etc.); ECTS based nonformal course; non-formal course (not ECTS based) certificate; informal learning activity evidence; ECTS based informal learning activity evidence)

Badge category (formal qualification / degree; non-formal certificate; record of experience / portfolio / badges)

Type of learning outcome (knowledge; skills; autonomy / responsibility)

Level of learning (EQF or NQF)

Mode of learning (online; face-to-face; blended; placement; workplace)

Activity type (workshop, seminar or conference; discussion; group work; teamwork; individual work; internship / placement; apprenticeship / shadowing; job experience; project work)

Volume of learning (in ECTS and contact hours)

X

$\mathrm{X}$

$\mathrm{X}$

X

X

$\mathrm{X}$

$\mathrm{X}$

$\mathrm{X}$

$\mathrm{X}$

$\mathrm{X}$

X

Type of assessment (formative (accumulative); summative (at a conclusion of a defined instructional period); or both)

Procedural requirements for learner authentication and ID verification (online assessment without ID verification; online assessment with ID verification (proctoring); ID verification with secure login + password in learning management system; ID verification with third party tool; ID verification against national ID databases; biometric ID verification; other)

Assessed by whom (peer assessment; self-assessment; teacher assessment; independent assessor (third party))

Format of assessment (automatic grading; manual grading; both, automatic and manual grading)

Grading scheme (pass or fail; $100 \%$ to $0 \%$; A+ (excellent) to F- (fail); 10 (excellent) to $0 \quad \mathrm{X}$ (fail) grade scale) 
Both in traditional learning and online learning grading scheme (pass or fail; $100 \%$ to $0 \%$; $\mathrm{A}+$ (excellent) to $\mathrm{F}$ - (fail); 10 (excellent) to 0 (fail) grade scale) need to be considered because of the possibilities of global learning and different grading traditions. This particularly concerns assessment of learning outcomes.

Compilation of the results from experts' interview, and what was referred above allows to indicate what quality criteria for assessment and recognition need to be included in a DB description metadata technical templates in virtual learning environments (Table 3). The criteria items are formulated as a proposal from the research, while the two supplementary columns of Table 2 illustrate whether a criterion is relevant for assessment or/and for recognition processes in HE.

\section{Lessons learned}

The research of this paper has revealed a rather superficial situation of usage of DB at the university. DB that were issued at the university were initiated by only several enthusiastic teachers who were eager to find new contemporary ways to motivate students by using a microcredential that is gaining its popularity among young people mostly outside academia in nonformal youth work and open professional development. However, as only a rather superficial badge metadata was being used by the teachers the badges that were issued to the students had little value due to the limited metadata that was provided within the badges. In other words, the information provided in the description of the badge lacked solid input regarding the assessment methods, activities/tasks carried out to receive the badge or the time required to perform the tasks.

A DB with such limited metadata offers also limited value for the student outside the given course where the badge was awarded. On the other hand a DB with a solid metadata behind it could serve as a separate microcredential that could be attractive and informative to the employers, who are willing to employ candidates with competencies that are additional to the academic ones, e.g, organizational skills, social skills, specific technological skills, etc.

The data gained from the literature research and expert interviews allowed forming standard quality criterions based requirements for DB metadata description. These research data-based criterions will be adopted in the university as standard requirements for DB metadata for university teachers willing to initiate a new DB. Accordingly, the same standard quality criterions will be applied if students would be willing to get recognition of a DB gained outside the university.

Another essential lesson learned during this research is the necessity of training for teachers about DB creation. The research of the existing DB issued in the university demonstrated a low value in this type of microcredentials due to the limited amount of metadata inscribed in DB. Teachers who were issuing DB viewed them more as a form of gamification than a solid contemporary microcredential.

Therefore, the applied result of this reseach paper is twofold: a creation research based metadata quality criterions for DB at the university and a clear need to provide training to university teachers about contemporary metadata based DB. 


\section{Conclusions}

To summarize our findings based on university DB metadata analysis, it reveals two predominate reasons why badges are issued to students:

a) To contribute to overall assessment strategy.

b) To assess soft skills by acknowledging certain personal professional skills or competences achieved or demonstrated.

At the university, badges are neither used to substitute conventional grading mechanisms, nor recognize students' prior achievements earned outside formal learning settings. The results also reveal the fact that metadata descriptions of badges are rather limited and short of significant information. Therefore, there is lack of information on students' achievements and parameters required for acquisition of the badge.

The results from expert interview confirm that DBs become of greater value if the information provided in the DB description metadata supplies data about the learning process and gives the evidence or answers that one needs, either as a university representative, a lecturer, or as an employer. It is important for the person recognizing the achievement to assure learner identification security, i.e. that this is the person who has actually participated in the learning process and has reached the indicated learning results. Although DB practices are improving, the problem still exists that DBs are very often misused: the metadata in their description does not provide necessary information, making it difficult for students to use badges for the recognition of their learning results, exporting and publishing them in other environments, and vice versa.

Research findings of this study allows formulation of new knowledge about the use of DBs for assessment and recognition, and provides the quality criteria for DB metadata descriptions, so that they would carry more value for assessment and recognition in HE. Therefore, the study will contribute to enhance the use of DBs in the studied institution as well as in other similar contexts.

The impact of the study is inclusion of the proposed list of quality criteria for DB metadata descriptions in institutional practices. That directly concerns the improvement of the value of DBs for students' assessment and recognition as DBs with rich and quality criteria based metadata descriptions will have a higher value in higher education.

\section{Acknowledgement}

This research has been funded by the research project "Open Online Learning for Digital and Networked Society" (3.3-LMT-K-712-01-0189) funded by the ESF and Lithuanian Research Council under High Level R\&D grant. 


\section{References}

Abramovich, S. (2016), Understanding digital badges in higher education through assessment, On the Horizon, 24(1), 126-131.

Abramovich, S., Schunn, C., Higashi, R. M. (2013). Are badges useful in education?: It depends upon the type of badge and expertise of learner. Educational Technology Research and Development, 61(2), 217-232.

Bernard, H. R., Wutich, A., Ryan, G. W. (2016). Analyzing Qualitative Data: Systematic Approaches. SAGE publications.

Bjornavold, J., Le Mouillour, I. (2009). Learning Outcomes in Validation and Credit Systems. European Journal of Vocational Training, 48(3), 27-47.

Boyer, B. (2018). Badges for information literacy: Not just digital stickers. Teacher Librarian, 45(5), 22 26.

Carey, K. L. (2017). An Analysis of Factors that Impact Diffusion and Adoption of Digital Badges.

Carey, K. L., Stefaniak, J. E. (2018). An exploration of the utility of digital badging in higher education settings. Educational Technology Research and Development, 66(5), 1211-1229.

Casilli, C., Hickey, D. (2016). Transcending conventional credentialing and assessment paradigms with information-rich digital badges. The Information Society, 32(2), 117-129.

Catalano, F., Doucet, K. J. (2013). Digital 'badges' emerge as part of credentialing's future. Institute for Credentialing Excellence, 203. aAvailable online at www . credentialingexcellence.org/p/cm/ld/fid

Cheng, Z., Watson, S. L., Newby, T. J. (2018). Goal setting and open digital badges in higher education. TechTrends, 62(2), 190-196.

Creswell, J. W. (2013). Qualitative Inquiry and Research Design: Choosing Among Five Approaches.

Devedžić, V., Jovanović, J. (2015). Developing open badges: A comprehensive approach. Educational Technology Research and Development, 63(4), 603-620.

Duncan, A. (2011). Digital badges for learning. Remarks by Secretary Duncan at 4th Annual Launch of the MacArthur Foundation Digital Media and Lifelong Learning Competition.

Dyjur, P., Lindstrom, G. (2017). Perceptions and uses of digital badges for professional learning development in higher education. TechTrends, 61(4), 386-392.

Fanfarelli, J. R., McDaniel, R. (2017). Exploring digital badges in university courses: Relationships between quantity, engagement, and performance. Online Learning, 21(2), n2.

Gibson, D., Coleman, K., Irving, L. (2016). Learning journeys in higher education: Designing digital pathways badges for learning, motivation and assessment. In Foundation of Digital Badges and MicroCredentials (pp. 115-138). Springer, Cham.

Gibson, D., Ostashewski, N., Flintoff, K., Grant, S., Knight, E. (2015). Digital badges in education. Education and Information Technologies, 20(2), 403-410.

Haldane, A., Wallace, J. (2009). Using technology to facilitate the Accreditation of Prior and Experiential Learning in developing personalised work-based learning programmes. A case study involving the University of Derby, UK. European Journal of Education, 44(3), 369-383.

Hickey, D. T., Chartrand, G. T. (2020). Recognizing competencies vs. completion vs. participation: Ideal roles for web-enabled digital badges. Education and Information Technologies, 25(2), 943-956.

Ifenthaler, D., Bellin-Mularski, N., Mah, D. K. (2016). Foundation of Digital Badges and Micro-Credentials. Switzerland: Springer International Publishing.

Iwata, J., Telloyan, J., Murphy, L., Wang, S., Clayton, J. (2017). The Use of a Digital Badge as an Indicator and a Motivator. International Association for Development of the Information Society.

Jones, W. M., Hope, S., Adams, B. (2018). Teachers' perceptions of digital badges as recognition of professional development. British Journal of Educational Technology, 49(3), 427-438.

Kehoe, A., Goudzwaard, M. (2015). ePortfolios, badges, and the whole digital self: How evidence-based learning pedagogies and technologies can support integrative learning and identity development. Theory Into Practice, 54(4), 343-351.

Law, P. (2015). Digital badging at The Open University: recognition for informal learning. Open Learning: The Journal of Open, Distance and e-Learning, 30(3), 221-234.

Mah, D. K. (2016). Learning analytics and digital badges: Potential impact on student retention in higher education. Technology, Knowledge and Learning, 21(3), 285-305. 
Mewburn, I., Freund, K., Rutherford, E. (2014). Badge Trouble: Piloting Open Badges at the Australian National University. Ascilite.

Muilenburg, L. Y., Berge, Z. L. (Eds.). (2016). Digital Badges in Education: Trends, Issues, and Cases. Routledge.

O’Byrne, W. I., Schenke, K., Willis, J. E., Hickey, D. T. (2015). Digital badges: Recognizing, assessing, and motivating learners in and out of school contexts. Journal of Adolescent \& Adult Literacy, 58(6), 451-454.

Parker, H. E. (2015). Digital Badges to Assess Bloom's Affective Domain. In The National Teaching \& Learning Forum (Vol. 4, No. 24, pp. 9-11).

Rimland, E., Raish, V. (Eds.). (2019). Micro-Credentials and Digital Badges. ALA TechSource.

Roy, S., Clark, D. (2019). Digital badges, do they live up to the hype?. British Journal of Educational Technology, 50(5), 2619-2636.

Singh, M., Duvekot, R. (2013). Linking Recognition Practices and National Qualifications Frameworks: International Benchmarking of Experiences and Strategies on the Recognition, Validation and Accreditation (RVA) of Non-Formal and Informal Learning. UNESCO Institute for Lifelong Learning. Feldbrunnenstrasse 58, 20148 Hamburg, Germany.

Stefaniak, J., Carey, K. (2019). Instilling purpose and value in the implementation of digital badges in higher education. International Journal of Educational Technology in Higher Education, 16(1), 1-21.

The Bologna Open recognition Declaration (2016). Retrieved May 5, 2020, from https: //www .openrecognition.org/bord

Waters, J. K. (2013). Career/college readiness: Digital badges. The Journal, 40(5), 14-19.

Wu, M., Whiteley, D., Sass, M. (2015). From girl scout to grown up: Emerging applications of digital badges in higher education. The Online Journal of Distance Education and e-Learning, 3(2), 48-52.

Zucker, L., Hicks, T. (2019). Alternative assessments, unintended consequences: The promise and peril of digital badges. Transformations: The Journal of Inclusive Scholarship and Pedagogy, 29(1), 113-123.

E. Trepulè is an associate professor at the Education Academy of Vytautas Magnus university (Lithuania) and researcher in several international research projects in the topics of technology enhanced learning, microcredentials in higher education, learning needs of a contemporary digital networked society, assessment and recognition of open online learning. Elena is lecturing in blended and distance learning form for the recent 7 years and is an assessing expert of a university board of accreditation of courses for distance learning mode.

A. Volungevičienė is a professor of Education and the director of Innovative Studies Institute at Vytautas Magnus University. She is the leader of the global grant research project, the chair of management board of EDEN - Digital Learning Europe, the coeditor in chief of the research journal „The International Journal of Education Technologies in Higher Education" and expert of international groups in open and online learning. Her research areas cover technology enhanced learning (TEL) integration into an organization, TEL curriculum designing and quality assurance, open and online learning recognition and assessment, digital credentialization, open learning environments and many more. 
M. Teresevičienè is a professor of Education at Vytautas Magnus University (Lithuania). Scientific interests include new digital technologies for lifelong learning. Is active in TEL (technology enhanced learning) topics, has interest in digital technologies, their role in the learning process and its management. Together with other researchers during the recent 10 years has published 6 monographs and over 60 research papers, is an editorial board member of 6 research journals and an active participant of international and national scientific and applied research projects.

R. Greenspon is a PhD student in the field of education at Vytautas Magnus university, Lithuania. Rasa's work is focusing on digital assessment and its methods and strategies within the learning environment. Her previous research involved the field of technology enhanced learning.

N. Costa is a Professor, Director of the PhD Program in Education, University of Aveiro, Portugal. Areas of research: Assessment and Evaluation in Education, Quality in Education, Teacher Education (from secondary school up to higher education), Staff development (from secondary school up to higher education). Competences and Skills includes coordination of national and international projects; monitoring and evaluation of research and professional programmes; supervision of research students and formation processes. 